Available online at http://jurnal.goretanpena.com/index.php/JSSR

\title{
SISTEM PENDUKUNG KEPUTUSAN MENENTUKAN KUALITAS BIBIT KELAPA SAWIT LAYAK TANAM PADA PT INDAH POCAN DENGAN WASPAS
}

\author{
Muhammad Dahria ${ }^{1}$, Hendyran Winata ${ }^{2}$, Ismawardi Santoso ${ }^{3}$, Sobirin $^{4}$ \\ STMIK Triguna Dharma,Medan \\ e-mail: ${ }^{1} \mathrm{~m} \_$dahria@ trigunadharma.ac.id
}

\begin{abstract}
PT Indah Pocan is a company engaged in the oil palm sector. PT Indah Pocan experienced unsatisfactory palm oil harvests, this affected employee performance. So PT Indah Pocan needs quality oil palm seeds to increase its yields. Therefore, PT Indah Pocan selected suitable oil palm seeds for planting. Therefore, it is necessary to overcome this problem, it is necessary to carry out a problem solving process by making decisions that can assist the field head in selecting suitable oil palm seeds for planting. In this case, a decision support system using the waspas method can be used to select more than one criterion, then the process of selecting the best results will be carried out. Thus the field head will be more effective in determining the quality of oil palm seeds suitable for planting.
\end{abstract}

Keywords: Decision Support System, Waspas Method, Oil Palm Seeds

\begin{abstract}
Abstrak: PT Indah Pocan merupakan perusahaan yang bergerak dalam bidang kelapa sawit. PT Indah Pocan mengalami panen kelapa sawit yang kurang memuaskan, hal ini mempengaruh kinerja karyawan. Maka PT Indah Pocan membutuhkan bibit kelapa sawit yang berkualitas untuk meningkatkan hasil panennya. Oleh karena itu PT Indah Pocan pemilihan bibit kelapa sawit yang layak tanam. Oleh karena itu dibutuhkan untuk mengatasi masalah tersebut maka perlu dilakukan proses pemecahan masalah dengan mengambil keputusan yang dapat membantu pihak kepala lapangan dalam pemilihan bibit kelapa sawit layak tanam. Dalam hal ini diterapkan sistem pendukung keputusan menggunkan metode waspas dapat digunakan untuk menyeleksi lebih dari satu kriteria, kemudian akan dilakukan proses menyeleksi hasil yang terbaik. Dengan demikian kepala lapangan akan lebih efektif dalam menentukan kualitas bibit kelapa sawit layak tanam.
\end{abstract}

Kata kunci: Sistem Pendukung Keputusan, Metode Waspas, Bibit Kelapa Sawit

\section{PENDAHULUAN}

PT Indah Pocan adalah salah satu PT yang bergerak dibidang kelapa sawit. PT Indah Pocan berpusat di Serdang Bedagai. Dalam PT indah Pocan sangat banyak melakukan pekerjaan, salah satunya dalah pemilihan bibit kelapa sawit yang layak tanam. Dalam pemilihan bibit kelapa sawit layak tanam secara subjektif sehingga pemilihan bibit kelapa sawit kurang efektif.

Untuk mengatasi masalah tersebut maka perlu dilakukan proses pemecahan masalah dengan penerapan sistem pengambil keputusan menggunakan metode waspas. Sistem pengambilan keputusan dengan penerapan metode ini digunakan untuk menyeleksi lebih dari satu kriteria, kemudian akan dilakukan proses menyeleksi hasil yang terbaik. Metode ini dapat membantu pihak kepala lapangan dalam proses pemilihan bibit kelapa sawit layak tanam. Dengan demikian pihak petugas akan lebih efektif dalam menentukan bibit kelapa sawit yang layak tanam. 
Available online at http://jurnal.goretanpena.com/index.php/JSSR

\section{METODE}

\section{Sistem Pendukung Keputusan}

Sistem Pendukung Keputusan merupakan salah satu sistem informasi komputer untuk membantu pemimpin dalam menangani berbagai permasalahan semi terstruktur ataupun tidak terstruktur dengan menggunakan data dan model yang menghasilkan berbagai alernatif keputusan (Pane \& Erwansyah, 2020).

Digunakan untuk membantu pengambilan keputusan dalam situasi yang semiterstruktur dan situasi yang tidak terstruktur, dimana tidak seorang pun tahu secara pasti bagaimana keputusan dibuat dan merupakan sistem informasi interaktif yang menyediakan informasi, pemodelan, dan pemanipulasian data (Widodo \& Nastoto, 2019)

Menurut (Erwansyah, 2019) dalam penentuan pengambilan keputusan memiliki tahapan yaitu Intellegence, Tahap Design, Tahap Choice.

\section{Metode WASPAS}

Metode WASPAS merupakan metode yang di gunakan untuk mengurangi kesalahan-kesalahan atau mengoptimalkan setiap penafsiran dalam memilih nilai tertinggi dan terendah (Suginan, Emi Suryani, Sapria, Ulandari Lubis, 2018).

Berikut merupakan langkah-langkah kerja dari metode Waspas yaitu:

1. Mempersiapkan Matriks $X$

2. Menormalisasi $\mathrm{R}_{\mathrm{ij}}$

3. Menghitung nilai Alternatif (Qi)

\begin{tabular}{|c|c|c|c|c|c|}
\hline 4 & NIGRECENS & 11 & 16 & 100 & 6,6 \\
\hline 5 & VIRECENS & 10 & 15 & 150 & 6,9 \\
\hline 6 & ALBENSCENS & 13 & 17 & 130 & 6,8 \\
\hline 7 & $\begin{array}{c}\text { DXP } \\
\text { LANGKAT }\end{array}$ & 12 & 11 & 120 & 6,5 \\
\hline
\end{tabular}

Dari hasil penelitian di PT Indah Pocan terdapat beberapa data yang dapat digunakan sebagai sampel dalam penelitian sebagai berikut:

Tabel 2 Kriteria Penilaian dan Bobot

\begin{tabular}{|c|c|c|c|}
\hline $\begin{array}{c}\text { Kriteri } \\
\mathrm{a}\end{array}$ & $\begin{array}{c}\text { Keteranga } \\
\mathrm{n}\end{array}$ & $\begin{array}{c}\text { Bobo } \\
\mathrm{t}\end{array}$ & $\begin{array}{c}\text { Normalisa } \\
\mathrm{si}\end{array}$ \\
\hline $\mathrm{C} 1$ & Umur & $17 \%$ & 0,17 \\
\hline $\mathrm{C} 2$ & $\begin{array}{c}\text { Jumlah } \\
\text { Pelepah }\end{array}$ & $23 \%$ & 0,23 \\
\hline $\mathrm{C} 3$ & $\begin{array}{c}\text { Tinggi } \\
\text { Tanaman }\end{array}$ & $27 \%$ & 0,27 \\
\hline $\mathrm{C} 4$ & $\begin{array}{c}\text { Diameter } \\
\text { Tanaman }\end{array}$ & $33 \%$ & 0,33 \\
\hline
\end{tabular}

Berdasarkan data yang sudah didapatkan, maka dilakukan konversi setiap kriteria untuk dapat dilakukan proses perhitungan kedalam metode WASPAS (Weight Aggragated Sum Product Assesment) (Barus et al., 2018). Berikut ini adalah tabel dari kriteria yang digunakan.

Tabel 3 Umur $\left(\mathrm{C}_{1}\right)$

\begin{tabular}{|c|c|c|}
\hline No & C1 & $\begin{array}{c}\text { Bobot } \\
\text { Alternatif }\end{array}$ \\
\hline 1. & 1 sampai 3 & 1 \\
\hline 2. & 4 sampai 6 & 2 \\
\hline 3. & 7 sampai 9 & 3 \\
\hline 4. & 10 sampai 12 & 4 \\
\hline 5. & 13 sampai 15 & 5 \\
\hline
\end{tabular}

Tabel 4 Jumlah Pelepah $\left(\mathrm{C}_{2}\right)$

\begin{tabular}{|c|c|c|c|c|c|}
\hline \multirow{2}{*}{ No } & \multirow{2}{*}{$\begin{array}{c}\text { Nama Bibit } \\
\text { Kelapa } \\
\end{array}$} & \multicolumn{4}{|c|}{ Nawit } \\
\cline { 3 - 6 } & C1 & C2 & C3 & C4 \\
\hline 1 & DURA & 8 & 12 & 100 & 6,3 \\
\hline 2 & PISIFERA & 9 & 14 & 110 & 6,5 \\
\hline 3 & TENERA & 12 & 13 & 115 & 6,5 \\
\hline
\end{tabular}

\begin{tabular}{|l|c|c|}
\hline No & Jumlah Pelepah & $\begin{array}{c}\text { Bobot } \\
\text { Alternatif }\end{array}$ \\
\hline 1. & 1 sampai 4 & 1 \\
\hline 2. & 5 sampai 8 & 2 \\
\hline 3. & 9 sampai 12 & 3 \\
\hline 4. & 13 sampai 16 & 4 \\
\hline 5. & 17 sampai 20 & 5 \\
\hline
\end{tabular}

Tabel 6 Tinggi Tanaman $\left(\mathrm{C}_{3}\right)$ 
Available online at http://jurnal.goretanpena.com/index.php/JSSR

\begin{tabular}{|c|c|c|}
\hline No & Tinggi Tanaman & $\begin{array}{c}\text { Bobot } \\
\text { Alternatif }\end{array}$ \\
\hline 1. & 100 sampai 110 & 1 \\
\hline 2. & 111 sampai 120 & 2 \\
\hline 3. & 121 sampai 130 & 3 \\
\hline 4. & 131 sampai 140 & 4 \\
\hline 5. & 141 sampai 150 & 5 \\
\hline
\end{tabular}

$$
\begin{aligned}
& \text { A34 }=3 / 5=0,6 \\
& \text { A44 }=4 / 5=0,8 \\
& \text { A54 }=5 / 5=1 \\
& \text { A64 }=5 / 5=1 \\
& \text { A74 }=3 / 5=0,6
\end{aligned}
$$

Dengan langkah-langkah perhitungan diatas maka didapatkan tabel data normalisasi matrik berikut ini:

Tabel 8 Normalisasi $x$ Bobot

\begin{tabular}{|l|c|c|}
\hline No & Diameter Tanaman & $\begin{array}{l}\text { Bobot } \\
\text { Alternatif }\end{array}$ \\
\hline 1. & 6 sampai 6,1 & 1 \\
\hline 2. & 6,2 sampai 6,3 & 2 \\
\hline 3. & 6,4 sampai 6,5 & 3 \\
\hline 4. & 6,6 sampai 6,7 & 4 \\
\hline 5. & 6,8 sampai 6,9 & 5 \\
\hline
\end{tabular}

\section{HASIL DAN PEMBAHASAN}

\begin{tabular}{|c|c|c|c|c|}
\hline \multirow{2}{*}{ Alt } & \multicolumn{4}{|c|}{ Kriteria } \\
\cline { 2 - 5 } & $\mathbf{C 1}$ & $\mathbf{C 2}$ & $\mathbf{C 3}$ & $\mathbf{C 4}$ \\
\hline A1 & $0,2^{*} 0,17$ & $0,6^{*} 0,23$ & $0,2^{*} 0,27$ & $0,4^{*} 0,33$ \\
\hline A2 & $0,6^{*} 0,17$ & $0,8^{*} 0,23$ & $0,2^{*} 0,27$ & $0,6^{*} 0,33$ \\
\hline A3 & $0,8^{*} 0,17$ & $0,8^{*} 0,23$ & $0,4^{*} 0,27$ & $0,6^{*} 0,33$ \\
\hline A4 & $0,8^{*} 0,17$ & $0,8^{*} 0,23$ & $0,2 * 0,27$ & $0,8^{*} 0,33$ \\
\hline A5 & $0,8^{*} 0,17$ & $08^{*} 0,23$ & $1^{*} 0,27$ & $1^{*} 0,33$ \\
\hline A6 & $1^{*} 0,17$ & $1^{*} 0,23$ & $0,6^{*} 0,27$ & $1^{*} 0,33$ \\
\hline A7 & $0,8^{*} 0,17$ & $0,6^{*} 0,23$ & $0,4^{*} 0,27$ & $0,6^{*} 0,33$ \\
\hline
\end{tabular}

Dari tabel nilai masing-masing kriteria akan dilakukan normalisasi data, yaitu:

a. Kriteria untuk $\mathrm{C} 1$

$$
\begin{aligned}
& \text { A11 }=1 / 5=0,2 \\
& \text { A21 }=3 / 5=0,6 \\
& \text { A31 }=4 / 5=0,8 \\
& \text { A41 }=4 / 5=0,8 \\
& \text { A51 }=4 / 5=0,8 \\
& \text { A61 }=5 / 5=1 \\
& \text { A71 }=4 / 5=0,8
\end{aligned}
$$

b. Kriteria untuk $\mathrm{C} 2$

$$
\mathrm{A} 12=3 / 5=0,6
$$$$
\mathrm{A} 22=4 / 5=0,8
$$$$
\mathrm{A} 32=4 / 5=0,8
$$$$
\mathrm{A} 42=4 / 5=0,8
$$$$
\text { A } 52=4 / 5=0,8
$$$$
\mathrm{A} 62=5 / 5=1
$$$$
\text { A72 }=3 / 5=0,6
$$

c. Kriteria untuk C3

$$
\mathrm{A} 13=1 / 5=0,2
$$$$
\mathrm{A} 23=1 / 5=0,2
$$$$
\mathrm{A} 33=2 / 5=0,4
$$$$
\mathrm{A} 43=1 / 5=0,2
$$$$
\mathrm{A} 53=5 / 5=1
$$$$
\mathrm{A} 63=3 / 5=0,6
$$$$
\mathrm{A} 73=2 / 5=0,4
$$

Tabel 9 Hasil Normalisasi x Bobot

\begin{tabular}{|l|c|c|c|c|}
\hline \multirow{2}{*}{$\begin{array}{c}\text { Alternati } \\
\text { f }\end{array}$} & \multicolumn{5}{|c|}{ Kriteria } \\
\cline { 2 - 5 } A1 & $\mathbf{C 1}$ & $\mathbf{C 2}$ & $\mathbf{C 3}$ & $\mathbf{C 4}$ \\
\hline \multirow{2}{*}{ A2 } & 0,03 & 0,13 & 0,05 & 0,13 \\
& 4 & 8 & 4 & 2 \\
\hline \multirow{2}{*}{ A3 } & $\begin{array}{c}0,10 \\
2\end{array}$ & $\begin{array}{c}0,18 \\
4\end{array}$ & $\begin{array}{c}0,05 \\
4\end{array}$ & $\begin{array}{c}0,19 \\
8\end{array}$ \\
\hline \multirow{2}{*}{ A4 } & $\begin{array}{c}0,13 \\
6\end{array}$ & $\begin{array}{c}0,18 \\
4\end{array}$ & $\begin{array}{c}0,10 \\
8\end{array}$ & $\begin{array}{c}0,19 \\
8\end{array}$ \\
\hline \multirow{2}{*}{ A5 } & 0,13 & 0,18 & 0,05 & 0,26 \\
& 6 & 4 & 4 & 4 \\
\hline \multirow{2}{*}{ A6 } & 0,13 & 0,18 & & \\
& 6 & 4 & 0,27 & 0,33 \\
\hline \multirow{2}{*}{ A7 } & 0,17 & 0,23 & 2 & 0,33 \\
\hline
\end{tabular}

Tabel diatas normalisasi setiap alternatif dikali bobot kriteria yang telah ditentukan.

a. Menghitung Nilai Q dan $\mathrm{W}$ $(x i j)^{\text {wj }}$ $\mathrm{Q}=0,5 \sum_{j=1}^{n} x i w j+0,5 \Pi_{\mathrm{j}=1}$ d. Kriteria untuk $\mathrm{C} 4$

A $14=2 / 5=0,4$ A24 $=3 / 5=0,6$

1. Nilai Alternatif A1 (Q1) 
Available online at http://jurnal.goretanpena.com/index.php/JSSR

$\mathrm{Q} 1=0,5 \sum(0,2 * 0,17)(0,6 * 0,23)(0,2 * 0$,

27) $(0,4 * 0,33)$

$\mathrm{Q} 1=0,5 \sum(0,034)+(0,138)+(0,054)+(0$, 132)

$\mathrm{Q} 1=0,5 * 0,358=0,179$

$\mathrm{Q} 1=0,5 \prod\left(0,2^{0,17}\right)\left(0,6^{0,23}\right)\left(0,2^{0,27}\right)\left(0,4^{0,3}\right.$ )

$\mathrm{Q} 1=0,5 \prod(0,76)+(0,89)+(0,65)+(0,74)$

$\mathrm{Q} 1=0,5 * 3,04=1,52$

$\mathrm{Q} 1=0,179+1,52=1,699$

2. Nilai Alternatif $A 2(\mathrm{Q} 2)$

$\mathrm{Q} 2=0,5 \sum(0,6 * 0,17)(0,8 * 0,23)(0,2 * 0$, 27) $(0,6 * 0,33)$ 198)

$\mathrm{Q} 2=0,5 \sum(0,102)+(0,184)+(0,054)+(0$,

$\mathrm{Q} 2=0,5 * 0,538=0,269$

$\left.{ }^{3}\right)$

$\mathrm{Q} 2=0,5 \prod\left(0,6^{0,17}\right)\left(0,8^{0,23}\right)\left(0,2^{0,27}\right)\left(0,6^{0,3}\right.$

$\mathrm{Q} 2=0,5 \prod(0,92)+(0,95)+(0,65)+(0,84)$

$\mathrm{Q} 2=0,5 * 3,36=1,68$

$\mathrm{Q} 2=0,269+1,68=1,949$

3. Nilai Alternatif A3 (Q3)

$\mathrm{Q} 3=0,5 \sum(0,8 * 0,17)(0,8 * 0,23)(0,4 * 0$,

27) $(0,6 * 0,33)$

$\mathrm{Q} 3=0,5 \sum(0,136)+(0,184)+(0,108)+(0$, 198)

$\mathrm{Q} 3=0,5 * 0,626=0,313$

$\mathrm{Q} 3=0,5 \prod(0,80,17)(0,80,23)(0,40,27)($ $0,60,33)$

$\mathrm{Q} 3=0,5 \prod(0,96)+(0,95)+(0,78)+(0,84)$

$\mathrm{Q} 3=0,5 * 3,53=1,765$

$\mathrm{Q} 3=0,313+1,765=2,078$

4. Nilai Alternatif A4 (Q4)

$\mathrm{Q} 4=0,5 \sum(0,8 * 0,17)(0,8 * 0,23)(0,2 * 0$, 27) $(0,8 * 0,33)$

$\mathrm{Q} 4=0,5 \sum(0,136)+(0,184)+(0,054)+(0$, 264)

$\mathrm{Q} 4=0,5 * 0,879=0,638$

$\mathrm{Q} 4=0,5 \prod(0,80,17)(0,80,23)(0,20,27)($

$0,80,33)$

$\mathrm{Q} 4=0,5 \prod(0,96)+(0,95)+(0,65)+(0,93)$

$\mathrm{Q} 4=0,5 * 3,49=1,745$

$\mathrm{Q} 4=0,68+1,745=2,425$

5. Nilai Alternatif A5 (Q5)

Q5 $=0,5 \sum(0,8 * 0,17)(0,8 * 0,23)(1 * 0,27$ )$(1 * 0,33)$
Q5 $=0,5 \sum(0,136)+(0,184)+(0,27)+(0,3$

3)

$\mathrm{Q} 5=0,5 * 0,92=0,46$

$\mathrm{Q} 5=0,5 \prod(0,80,17)(0,80,23)(1,27)(1,3$

3)

$\mathrm{Q} 5=0,5 \prod(0,96)+(0,95)+(1)+(1)$

$\mathrm{Q} 5=0,5 * 3,91=1,955$

$\mathrm{Q} 5=0,46+1,955=2,415$

6. Nilai Alternatif A6 (Q6)

$\mathrm{Q} 6=0,5 \sum(1 * 0,17)(1 * 0,23)(0,6 * 0,27)$

$(1 * 0,33)$

$\mathrm{Q} 6=0,5 \sum(0,17)+(0,23)+(0,162)+(0,33$

)

$\mathrm{Q} 6=0,5 * 0,892=0,446$

$\mathrm{Q} 6=0,5 \prod(1,17)(10,23)(0,60,27)(10,3$

3)

$\mathrm{Q} 6=0,5 \prod(1)+(1)+(0,87)+(1)$

$\mathrm{Q} 6=0,5 * 3,87=1,935$

$\mathrm{Q} 6=0,446+1,935=2,381$

7. Nilai Alternatif A7 (Q7)

Q7 $=0,5 \sum(0,8 * 0,17)(0,6 * 0,23)(0,4 * 0$,

27) $(0,6 * 0,33)$

Q7 $=0,5 \sum(0,136)+(0,138)+(0,108)+(0$, 198)

$\mathrm{Q} 7=0,5 * 0,58=0,29$

$\mathrm{Q} 7=0,5 \prod(0,80,17)(0,60,23)(0,40,27)($

$0,60,33)$

$\mathrm{Q} 7=0,5 \prod(0,96)+(0,89)+(0,78)+(0,84)$

Q7 $=0,5 * 3,47=1,735$

$\mathrm{Q} 7=0,29+1,735=1,025$

Dari perhitungan indeks waspas (Qi) diatas maka diperoleh tabel peringkat indeks waspas.

\begin{tabular}{|c|c|c|c|}
\hline $\begin{array}{c}\text { Kode } \\
\text { Alternat } \\
\text { if }\end{array}$ & Inisial Bibit & $\begin{array}{c}\text { Bob } \\
\text { ot }\end{array}$ & $\begin{array}{c}\text { Rangki } \\
\text { ng }\end{array}$ \\
\hline A1 & DURA & $\begin{array}{c}1,69 \\
9\end{array}$ & 6 \\
\hline A2 & PISIFERA & $\begin{array}{c}1,94 \\
9\end{array}$ & 5 \\
\hline A3 & TENERA & $\begin{array}{c}2,07 \\
8\end{array}$ & 4 \\
\hline A4 & $\begin{array}{c}\text { NIGRECEN } \\
\text { S }\end{array}$ & $\begin{array}{c}2,42 \\
5\end{array}$ & 1 \\
\hline
\end{tabular}


Available online at http://jurnal.goretanpena.com/index.php/JSSR

\begin{tabular}{|c|c|c|c|}
\hline A5 & VIRECENS & $\begin{array}{c}2,41 \\
5\end{array}$ & 2 \\
\hline A6 & $\begin{array}{c}\text { ALBENSCE } \\
\text { NS }\end{array}$ & $\begin{array}{c}2,38 \\
1\end{array}$ & 3 \\
\hline A7 & $\begin{array}{c}\text { DXP } \\
\text { LANGKAT }\end{array}$ & $\begin{array}{c}1,02 \\
5\end{array}$ & 7 \\
\hline
\end{tabular}

Dari tabel diatas diperoleh data bahwa A4 nilai indeks waspas terbesar yaitu 2,425 sehingga dalam penelitian ini A4 atas nama bibit kelapa sawit NIGRECENS peringkat pertama dalam perangkingan menggunakan metode WASPAS (Weight Aggragated Sum Product Assesment).

\section{SIMPULAN}

Dari hasil pembahasan dari bab-bab sebelumnya maka dapat diambil kesimpulan sebagai berikut:

1. Untuk menentukan kelayakan bagi calon penerima bibit padi unggul pada Desa Sibonor Ompu Ratus dengan menggunakan suatu sistem pendukung sistem pendukung keputusan dengan metode VIKOR dibutuhkan beberapa kriteria agar pembagian lebih objek dan merata.

2. Cara menerapkan metode VIKOR (Visekriterjumsko Kompromisno Rangiranje) dalam menentukan kelayakan bagi calon penerima bibit padi unggul pada Desa Sibonor Ompu Ratus dengan menentukan kriteria, bobot kriteria, nilai data alteratif yang kemudian menentukan nilai $\mathrm{R}$ dan $\mathrm{S}$, kemudian menghitung nilai alternatif (Qi) dan akan didapatkan nilai perangkingan yaitu nilai akhir untuk hasil keputusan yang akan diambil.

\section{DAFTAR PUSTAKA}

Barus, S., Sitorus, V. M., Napitupulu, D., Mesran, M., \& Supiyandi, S. (2018).

\begin{abstract}
Sistem Pendukung Keputusan Pengangkatan Guru Tetap Menerapkan Metode Weight Aggregated Sum Product Assesment (WASPAS). Jurnal Media Informatika Budidarma, 2(2), 1015.

https://doi.org/10.30865/mib.v2i2.59 4
\end{abstract}

Erwansyah, K. (2019). Sistem Pendukung Keputusan Menentukan Mitra Kerja Entri Data Baru Pada Badan Pusat Statistik Kota Medan Menggunakan Metode MOORA ( Multi Objective Optimization On The Basis Of Ratio Analysis ). Sains Dan Komputer (SAINTIKOM), 18(1), 35-40. https://ojs.trigunadharma.ac.id/index .php/jis/article/view/101

Pane, D. H., \& Erwansyah, K. (2020). Model Prioritas Pemilihan Daerah Pembangunan Tower Telekomunikasi Berbasis Kombinasi Metode AHP dan Metode Moora. Jurnal Ilmiah Teknik Informatika Dan Sistem Informasi (JUTISI), 9(2), 11-22. http://ojs.stmikbanjarbaru.ac.id/index.php/jutisi/arti cle/view/491

Suginan, Emi Suryani, Sapria, Ulandari Lubis, M. (2018). Sistem Pendukung Keputusan Penerima Bantuan Siswa Miskin Menerapkan Metode WASPAS dan MOORA. Seminar Nasional Sains \& Teknologi Informasi, 719-727.

Widodo, W., \& Nastoto, I. (2019). Sistem Pendukung Keputusan Dengan Menggunakan Menggunakan Metode Multi Atribute Utility Theory (Maut) Untuk Penentuan Bantuan Rumah Tinggal Sehat. Indonesian Journal of Business Intelligence (IJUBI), l(2), 76. https://doi.org/10.21927/ijubi.v1i2.9 11 